\title{
Foetal umbilical artery doppler versus NST as predictors of adverse perinatal outcome in severe preeclampsia and foetal growth restriction
}

\author{
Amandeep Raj ${ }^{1}$, Reema Kumar Bhat ${ }^{2}$, S. Prajwal ${ }^{3}$, Rao P. S. ${ }^{3 *}$
}

\author{
${ }^{1}$ Department of Obstetrics and Gynaecology, Military Hospital, Gwalior, Madhya Pradesh, India \\ ${ }^{2}$ Department of Obstetrics and Gynaecology, Army Hospital RR, New Delhi, India \\ ${ }^{3}$ Department of Obstetrics and Gynaecology, Command Hospital AF, Bangalore, Karnataka, India
}

Received: 08 April 2017

Accepted: 17 April 2017

\section{*Correspondence:}

Dr. Rao P. S.,

E-mail: doctorpsrao@gmail.com

Copyright: ( $)$ the author(s), publisher and licensee Medip Academy. This is an open-access article distributed under the terms of the Creative Commons Attribution Non-Commercial License, which permits unrestricted non-commercial use, distribution, and reproduction in any medium, provided the original work is properly cited.

\section{ABSTRACT}

Background: With the advent of electronic foetal monitoring, a relationship between foetal movement and foetal heart rate was observed and that relationship formed the basis for non-stress test (NST). Doppler USG plays an important role in foetal growth restriction (FGR) pregnancies where hemodynamic rearrangements occur in response to foetal hypoxemia. It is now proved that significant Doppler changes occur with reduction in foetal growth at a time when other foetal well-being tests are still normal. This study was done to find out the comparative usefulness of Doppler and NST in the management of FGR and severe preeclampsia and subsequent correlation with perinatal outcome.

Methods: This prospective study was conducted on pregnant women with severe preeclamsia and/or FGR beyond 30 weeks of gestation at AHRR Delhi. 50 pregnancies complicated with severe preeclampsia and/or FGR beyond 30 weeks of gestation were selected. Patients meeting the inclusion criteria were subjected to NST. Umbilical arterial Doppler flow was obtained at weekly or twice weekly interval depending on the severity by pulsed wave color doppler indices were measured during foetal apnea by the same examiner at the free loop site where the clearest waveform signal could be visualized. Of 3 measurements, the mean average of S/D ratio was recorded and followed up with serial Doppler assessment and non-stress test. Data was collected and statistical analysis was carried out.

Results: The Doppler showed changes earlier than NST giving a significant lead time of up to 20 days with an average of 4.94 days. The UA S/D had the highest sensitivity (88\%) and diagnostic accuracy (94\%) in predicting the adverse perinatal outcome. The sensitivity and specificity of Doppler as compared to NST was $82.6 \%$ and $63.0 \%$ respectively with a diagnostic accuracy of $72 \%$. The Doppler has negative predictive value of $80.95 \%$ and positive predictive value of $65.5 \%$. Color Doppler has diagnostic accuracy of $72 \%$. The mortality rate in reversal of diastolic flow was $77.77 \%$ and in absent UA flow was $16.66 \% .12 \%$ foetuses were found to have AEDV in UA and among them $66.66 \%$ had both FGR+PE as maternal complication. There was $83.33 \%$ rate of LSCS, $16.66 \%$ neonatal mortality rate, $83.33 \%$ NICU stay rate and $66.66 \%$ complication rate in neonates. Whereas $18 \%$ had REDV and among that $88.88 \%$ had both FGR+PE as maternal complication, a similar rate of LSCS, $77.77 \%$ rate of neonatal mortality, $100 \%$ NICU stay and $66.66 \%$ complication rate in the neonates.

Conclusions: Combined foetal testing modalities such as Doppler, NST and biophysical profile provide a wealth of information regarding foetal health. Integrated foetal testing would be ideal for individualized care of the preterm compromised foetuses for timed intervention.

Keywords: Colour doppler, FGR, NST, Preeclampsia 


\section{INTRODUCTION}

With the advent of electronic foetal monitoring, a relationship between foetal movement and foetal heart rate was observed and that relationship formed the basis for non-stress test (NST). NST utilizes the observation that the occurrence of accelerations of the foetal heart rate in response to foetal movements is a reliable indicator of immediate foetal well-being. ${ }^{1}$

Antepartum surveillance tests to evaluate foetal health have been the focus of intense interest for more than three decades. There are many tests available today, each with its advantages and disadvantages. Non-stress test (NST) is the most widely used test and it reflects oxygenation of brain. Doppler plays an important role in foetal growth restriction (FGR) pregnancies where hemodynamic rearrangements occur in response to foetal hypoxemia. It is now proved that significant Doppler changes occur with reduction in foetal growth at a time when other foetal well-being tests are still normal.

In general, the presence of accelerations and normal FHR variability are findings which indicate the foetal normoxemia. ${ }^{2}$ The decelerations in FHR ante partum, in turn, are indicative of abnormalities. Late decelerations are mediated by stimulation of chemoreceptors in situations of foetal hypoxemia. ${ }^{3}$ Prolonged decelerations most often are associated with the foetal compromise. ${ }^{4}$ Elevated basal FHR and variability reduction are additional signs of foetal metabolic acidosis. ${ }^{5}$

The NST appears to be an excellent predictor of the healthy foetuses. The test is very good at predicting the foetuses that does not require acute or premature obstetric intervention, it thereby prevents pregnancies from being subjected to unnecessary iatrogenic risks and from incurring tremendous medical and emotional costs. The NST is simpler, less invasive, less time-consuming, and less expensive than its predecessor, the CST. It may be conducted in the outpatient setting with less skilled personnel. If the NST is to remain an important diagnostic modality, the issues of interpretative criteria, test conditions, and population composition must be reconsidered.

The antepartum assessment of foetal well being has become an integral part of management of both high risk and low risk pregnancies. The goal of various ante partum foetal surveillance techniques is to detect foetal distress so as to prevent foetal morbidity and mortality. Hence, these techniques aim to identify those babies that are at risk of preventable morbidity or mortality from uteroplacental insufficiency due to maternal risk factors, placental disorders or foetal disease.

This study was done to find out the comparative usefulness of Doppler and NST in the management of FGR and severe preeclampsia and subsequent correlation with perinatal outcome.

\section{METHODS}

This prospective study was conducted at Army Hospital Research and Referral New Delhi. 50 pregnancies complicated with severe preeclampsia and/or FGR beyond 30 weeks of gestation were selected. Singleton pregnancies beyond 30 weeks period of gestation with severe preeclampsia, FGR or with both FGR and Preeclampsia and with cephalic presentation were included.

Pregnancies before 30 weeks period of gestation, patients with multiple pregnancy, abruptio placenta, eclampsia severe anemia, severe heart disease, $\mathrm{Rh}$ isoimmunisation, severe CPD and patients presenting in latent or active phase of labour were excluded. Patients meeting the inclusion criteria were subjected to NST at least twice weekly, and even daily in severe cases.

NST was done for 20 min duration. The test was continued for $40 \mathrm{~min}$ in case of non-reassuring status. Umbilical arterial Doppler flow was obtained at weekly or twice weekly interval depending on the severity by pulsed wave color Doppler triplex ultrasound system, using Trans abdominal curvilinear transducers. After foetal biometry for confirmation of gestational age, Doppler indices were measured during foetal apnea by the same examiner at the free loop site where the clearest waveform signal could be visualized.

Of 3 measurements, the mean average of S/D ratio was recorded. The patients were followed by serial Doppler assessment and non-stress test. The results of the last Doppler and NST within one week of delivery was considered in the subsequent correlation with perinatal outcome. The time interval in days between the first abnormal Doppler and the development of abnormal NST was used to calculate the lead time.

Based on NST trace and color Doppler studies, the study population was divided into four groups; A $(n=17)$ normal NST and Normal Doppler, B $(n=10)$ Normal NST and Abnormal Doppler, C ( $\mathrm{n}=04)$ Abnormal NST and Normal Doppler and D $(n=19)$ Abnormal NST and Abnormal Doppler. Data analysis was carried out using stata 9.0 (college Statin, Texas USA). Data were presented as number $(\%)$ or mean $\pm \mathrm{SD} /$ Median (MinMax) as appropriate. Diagnostic evaluation of color Doppler against NST was found using sensitivity $(95 \%$ C.I.), specificity (95\% C.I.), diagnostic accuracy (95\% C.I.) and LR + (95\% C.I.).

The characteristics of pregnancy complications and pregnanacy outcomes were compared among the four groups using Fisher's exact test/Kruskal-Wallis test as appropriate. The odds associated with both abnormal procedure for pregnancy complications and pregnancy outcomes was done using logistics regression analysis. The results were reported as OR (95\% C.I). The P value less than 0.05 was considered statistically significant. 


\section{RESULTS}

A total of 50 women satisfied the inclusion criteria for the study. As shown in Table 1 mean age of the subjects studied was 28.7 years ranging from 21-39 years. Out of the 50 subjects $24(48.0 \%)$ were multigravida and 26 $(52.0 \%)$ were Primigravida who were admitted at an average POG of 33.11 weeks with the range of $28-38$ wks. Mean POG at delivery was at 34.29 weeks and ranged from 30-38.14 weeks.

Table 1: Demographic characteristics of study subjects $(\mathbf{n}=\mathbf{5 0})$.

\begin{tabular}{|l|l|}
\hline $\begin{array}{l}\text { Demographic } \\
\text { characteristic }\end{array}$ & Mean \pm SD (Min -Max) \\
\hline $\begin{array}{l}\text { Age (years) } \\
\text { Parity }\end{array}$ & $28.7 \pm 4.0(21-39)$ \\
\hline Multigravida & $\mathrm{N}(\%) 24(48.0 \%)$ \\
\hline Primigravida & $\mathrm{N}(\%) 26(52.0 \%)$ \\
\hline POG at admission & 33.11 wks \pm 2.38 weeks $(28-38)$ \\
\hline POG at delivery & $34.29 \pm 2.22(30-38.14)$ \\
\hline
\end{tabular}

Table 2 shows the maternal complications in the study subjects. $36 \%$ of the women had FGR, $16 \%$ had preeclampsia and $48 \%$ had both FGR + PE. Overall LSCS rate in the subjects was $72 \%$ and rate of vaginal delivery was $28 \%$. Twenty-nine percent of multigravidas had a history of preeclampsia in the previous pregnancy.
$48 \%$ of the study population had a combination of preeclampsia and FGR. There were 17 women where both NST and Doppler were normal (Group A), while both tests were abnormal in 19 women (Group D).

Table 2: Maternal complications.

\begin{tabular}{|c|c|}
\hline Maternal complications & $\mathbf{N}(\%)$ \\
\hline \multicolumn{2}{|l|}{ Pregnancy complication } \\
\hline FGR & $18(36)$ \\
\hline Preeclampsia. & $08(16)$ \\
\hline FGR+Preeclampsia & $24(48)$ \\
\hline \multicolumn{2}{|l|}{ Mode of delivery } \\
\hline Elective LSCS & $08(16)$ \\
\hline Emergency LSCS & $28(56)$ \\
\hline FTNVD & $05(10)$ \\
\hline PTVD18 (36\%) & $09(18)$ \\
\hline
\end{tabular}

However, Group C with normal Doppler and abnormal NST was small for comparison having only four women. Group B with normal NST and abnormal Doppler had 10 cases. There were 29 women with abnormal Doppler findings and 23 with abnormal NST.

Table 3 shows the maternal complications, mode of delivery, and perinatal outcome in the different groups. Group A where both test results were normal had majority of cases $(58.8 \%$; 10/17) with only FGR and had the least morbidity.

Table 3: Pregnancy complications, mode of delivery, perinatal outcome and neonatal characteristics.

\begin{tabular}{|c|c|c|c|c|}
\hline & Group A & Group B & Group C & Group D \\
\hline & $(n=17)$ & $(\mathbf{n}=\mathbf{1 0})$ & $(n=4)$ & $(\mathbf{n}=19)$ \\
\hline & NST-N & NST-N & NST-Ab & NST-Ab \\
\hline & Doppler-N & Doppler-Ab & Doppler-N & Doppler-Ab \\
\hline Mean Age (years) & 28.35 & 26.5 & 33.25 & 29.10 \\
\hline Range (years) & $24-35$ & $22-32$ & $30-39$ & $23-36$ \\
\hline Mean period of gestation at admission (weeks) & 35.10 & 32.67 & 31.9 & 32.51 \\
\hline Range & $33.71-36.57$ & $28-36.14$ & 30.3- 33.7 & $29-38$ \\
\hline \multicolumn{5}{|l|}{ Pregnancy complication } \\
\hline Preeclampsia & $4(23.53 \%)$ & $1(10.00 \%)$ & $1(25.0 \%)$ & $2(10.53 \%)$ \\
\hline FGR & $10(58.82 \%)$ & $5(50.0 \%)$ & - & $03(15.79 \%)$ \\
\hline Preeclampsia + FGR & $3(17.65 \%)$ & $4(40.0 \%)$ & $3(75.0 \%)$ & $14(73.68 \%)$ \\
\hline \multicolumn{5}{|l|}{ Mode of delivery } \\
\hline Vaginal & $8(47.06 \%)$ & $3(30.0 \%)$ & - & $3(15.79 \%)$ \\
\hline Cesarean & $9(52.94 \%)$ & $7(70.0 \%)$ & $4(100 \%)$ & $16(84.21 \%)$ \\
\hline \multicolumn{5}{|l|}{ Perinatal outcome } \\
\hline Survival & $16(94.12 \%)$ & $09(90 \%)$ & $03(75 \%)$ & $10(52.63 \%)$ \\
\hline Perinatal death & $01(5.88 \%)$ & $01(10 \%)$ & $01(25 \%)$ & $09(47.37 \%)$ \\
\hline \multicolumn{5}{|l|}{ Neonatal characteristics } \\
\hline Period of gestation (weeks) & 35.84 & 34.41 & 32.5 & 33.23 \\
\hline Preterm babies & $14(82.35 \%)$ & $7(70.0 \%)$ & $4(100 \%)$ & $18(94.74 \%)$ \\
\hline Average birth weight (g) & 2119 & 1674 & 1535 & 1542 \\
\hline APGAR $<7$ at 5 minutes & $02(11.6 \%)$ & $02(20 \%)$ & $01(25 \%)$ & $11(57.89 \%)$ \\
\hline Admission to NICU & $07(41.18 \%)$ & $07(70.0 \%)$ & $4(100 \%)$ & $18(94.74 \%)$ \\
\hline Neonatal complications & $01(5.88 \%)$ & $04(40 \%)$ & $1(25 \%)$ & $14(73.68 \%)$ \\
\hline
\end{tabular}


Group D which had the maximum number of cases of combined preeclampsia with FGR $(73.68 \%$; 14/19), had both the test results abnormal, and had the worst perinatal outcome associated with prematurity and low birth weight-(mean birth weight about 577 gm less when compared to that in Group A).

Table 4: Comparison of perinatal outcome between groups.

\begin{tabular}{|lllllll|}
\hline & Group A vs D & \multicolumn{3}{l|}{ Group B vs D } \\
\hline Perinatal factors & P value & OR & CI & P value & OR & CI \\
\hline PE + FGR & 0.003 & 2.496 & $(1.373-4.54)$ & 0.056 & 2.415 & $(0.976-5.976)$ \\
\hline Cesarean delivery & 0.050 & 1.68 & $(.999-2.824)$ & 0.376 & 1.512 & $(0.605-3.775)$ \\
\hline Perinatal deaths & 0.018 & 2.433 & $(1.164-5.085)$ & 0.069 & 14 & $(0.922-8.783)$ \\
\hline Preterm babies & 0.264 & 1.57 & $(0.712-3.454)$ & 0.099 & 2.78 & $(0.826-9.34)$ \\
\hline APGAR < 7 at 5 min & 0.008 & 2.18 & $(1.22-3.88)$ & 0.063 & 2.345 & $(0.955-5.76)$ \\
\hline NICU admission & 0.004 & 2.957 & $(1.40-6.213)$ & 0.099 & 2.77 & $(0.826-9.34)$ \\
\hline Neonatal complications & 0.001 & 3.552 & $(1.67-7.55)$ & 0.084 & 2.05 & $(0.91-4.62)$ \\
\hline
\end{tabular}

The statistical significance for perinatal outcome in Group A vs D and Group B vs D are shown in Table 4. Presence of preeclampsia with FGR significantly increased perinatal mortality $(\mathrm{P}=0.003)$, perinatal deaths $(\mathrm{P}=0.018)$ and NICU admissions $(\mathrm{P}=0.004)$ and neonatal complications $(\mathrm{P}=0.001)$ in Group $\mathrm{D}$ when compared to those in Group A. However there was no statistically significant difference between Groups A and D regarding route of delivery and prematurity. The number in Group $\mathrm{C}$ was too small for statistical comparison. Foetuses in Group B (normal NST, abnormal Doppler) were more advanced in gestation and had better neonatal outcome compared to those in Group D. Perinatal deaths $(\mathrm{P}=0.069)$, prematurity $(\mathrm{P}=0.099)$, and neonatal complications $(\mathrm{P}=0.084)$ were significantly more in Group D compared to those in Group B but statistically there was borderline difference.

Table 5: Neonatal outcomes.

\begin{tabular}{|ll|}
\hline Neonatal Outcome & N $(\%)$ \\
\hline Birth weight & $1.764 \pm 0.493(0.67-2.67)$ \\
\hline Sex & $23(46 \%)$ \\
\hline Male & $27(54 \%)$ \\
\hline Female & \\
\hline Perinatal mortality & $12(24 \%)$ \\
\hline Neonatal death & $38(76 \%)$ \\
\hline Survival & \\
\hline APGAR $<7$ at 5 min & $16(32 \%)$ \\
\hline Yes & $34(68 \%)$ \\
\hline No & $36(72 \%)$ \\
\hline NICU stay & $14(28 \%)$ \\
\hline Yes & $20(40 \%)$ \\
\hline No & $30(60 \%)$ \\
\hline Complications developed & \\
\hline Yes & \\
\hline No & \\
\hline
\end{tabular}

Table 5 represents the neonatal outcomes. There was one intrauterine death and eleven neonatal deaths in the study population. The neonatal death in Group A was from pulmonary haemorrhage due to FGR on 7th neonatal day. Major causes of neonatal death were pulmonary haemorrhage, septicaemia, and respiratory distress syndrome. Highest perinatal mortality and neonatal morbidity were seen in Group D where both tests were abnormal. Majority of women showed abnormal Doppler changes prior to NST.

Table 6: Diagnostic test evaluation.

\begin{tabular}{|c|c|c|}
\hline Parameter & Estimate & $\begin{array}{l}\text { Lower- } \\
\text { Upper } 95 \% \\
\text { CIs }\end{array}$ \\
\hline Sensitivity & $82.6 \%$ & $(62.9,93.0)$ \\
\hline Specificity & $63.0 \%$ & $(44.2,78.5)$ \\
\hline Positive predictive value & $65.5 \%$ & $(47.3,80.1)$ \\
\hline Negative predictive value & $80.95 \%$ & $(60,92.33)$ \\
\hline Diagnostic accuracy & $72 \%$ & $(58.3,82.5)$ \\
\hline $\mathrm{LR}+$ & 2.23 & $(1.8-2.8)$ \\
\hline
\end{tabular}

Table 6 compares the Color Doppler as a diagnostic test to the conventional NST. The sensitivity and specificity of Doppler as compared to NST is $82.6 \%$ and $63.0 \%$ respectively. In this study Doppler has negative predictive value of $80.95 \%$ and positive predictive value of $65.5 \%$. Color Doppler has diagnostic accuracy of $72 \%$. The likelihood ratio of 2.23 is significant.

\section{Lead time calculation}

The lead time is the time interval between the POG at which Color Doppler got abnormal at the first time and the POG at which the NST first got abnormal. This lead time varied between 0-20 days with a mean of 4.94 days. It was observed that lead time was shorter in cases with preeclampsia. Longer lead time was seen in cases with only FGR without other concomitant maternal disease. The lead time was seen only in Group ' $D$ ' whereas in Group ' $\mathrm{B}$ ' babies were delivered even before the NST had become abnormal and therefore there was no lead time. 


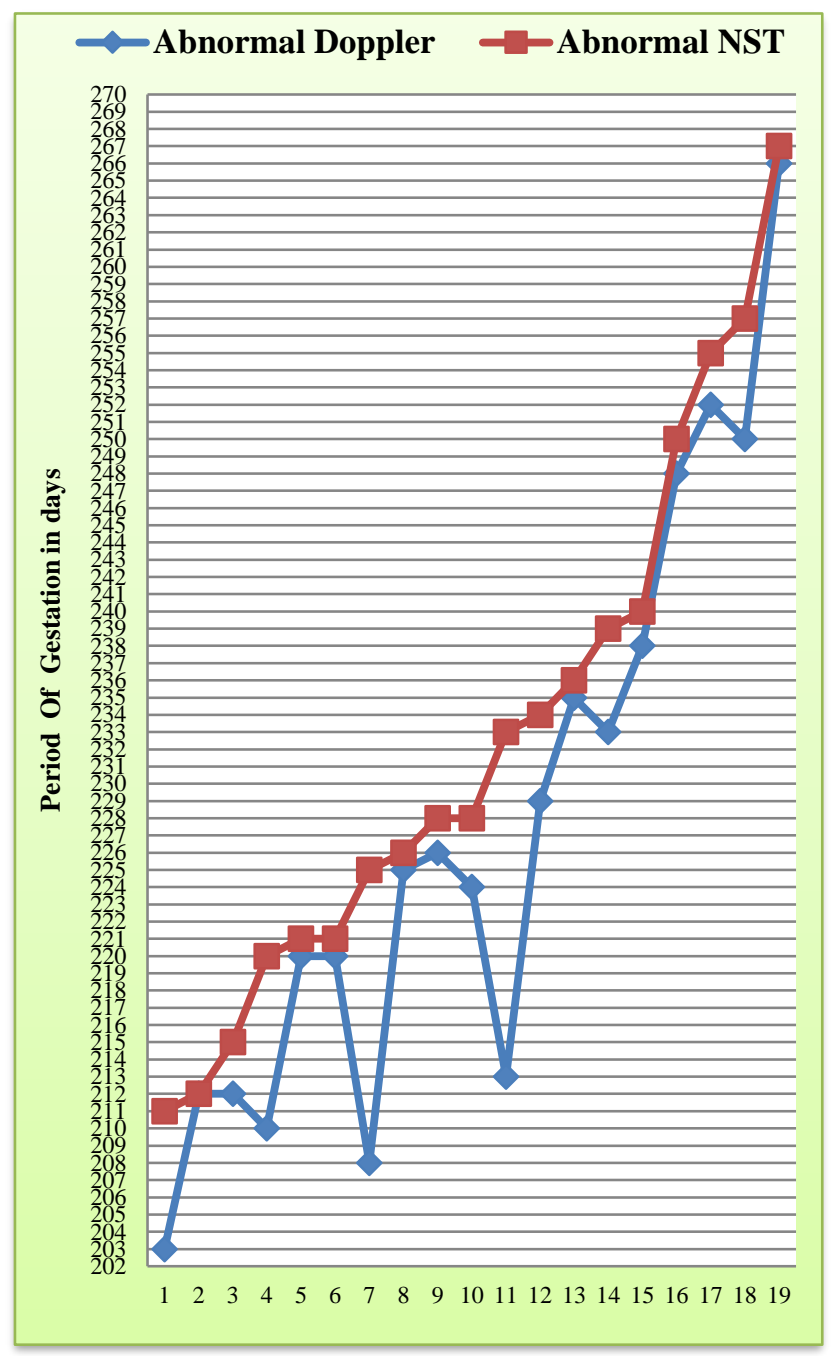

Figure 1: Lead time calculation in Group D.

\section{DISCUSSION}

On assessing foetal Doppler and NST in a group of women with high risk pregnancy comprising of FGR and/or Preeclampsia it is evident that when both NST and Doppler are abnormal, the baby weight and gestational age at birth are low and perinatal mortality and neonatal morbidity are high. Though both test results were effective in predicting abnormal outcome, the significant advantage of doppler over NST observed in this study in Group D was that doppler showed changes earlier than NST giving a significant lead time of up to 20 days with an average of 4.94 days. This lead time is very important as babies can be delivered in this period or can be followed up in this interim period to gain a little more pulmonary maturity, which may be crucial for a preterm foetuses. Steroid prophylaxis can be administered during this period in preterm foetuses.

The Growth Restriction Intervention Trial (GRIT), which was designed to time delivery in compromised preterm foetuses, showed that delaying delivery to increase maturity in severe hypoxemia increased stillbirths to nearly fivefold while deaths before discharge fell by one third. ${ }^{6}$ Foetal heart rate abnormalities occur much later in the decompensation phase, which is a late sign of foetal compromise. Similarly, in the current study the significant lower birth weight of foetuses when both Doppler and NST are abnormal (Group D) indicates that these foetuses suffer from a more severe degree of placental insufficiency. Though Doppler was abnormal in both $\mathrm{B}$ and $\mathrm{D}$ groups, perinatal outcome was better in Group B. When neonatal survival prospects are good it is better to deliver the compromised foetuses than to monitor till the development of abnormal NST as is evident from the perinatal outcome in Group B. These babies were less compromised and were relatively more advanced in gestation. So, early intervention was possible.

Arduini et al in their study observed a lead time ranging from 1 to 26 days and was shorter in the presence of preterminal Doppler changes like pulsatile umbilical vein and in preeclampsia. $^{7}$ Longer time interval between abnormal Doppler and NST was seen in few cases of idiopathic FGR detected early in gestation. This is because smaller foetuses have lowered nutritional and oxygen requirements allowing them to develop longer metabolic adaptations reflected by an abnormal Doppler. There is quick deterioration of placental function in the presence of preeclampsia resulting in shorter lead time. However, a tendency to have shorter lead time was present in subjects having preeclampsia, no such statistically significant relationship was found in this current study where the shortest lead time was zero days (subject having FGR+PE) and the longest was 20 days.

A cross-sectional study was performed by Ozeren M, et al on 125 normal pregnancies and 62 preeclamptic patients at 31-40 weeks of gestation. ${ }^{8}$ The UA S/D had the highest sensitivity (88\%) and diagnostic accuracy (94\%) in predicting the adverse perinatal outcome. The MCA PI/UA PI ratio showed the highest predictive value in determining FGR by a sensitivity of $84 \%$ and a diagnostic accuracy of $87 \%$. Both abnormal umbilical Doppler indices and cerebral-umbilical ratio are strong predictors of FGR and of adverse perinatal outcome in preeclampsia. The MCA PI alone is not a reliable indicator. In the current study as seen in Table 6 which compares the Color Doppler as a diagnostic test to the conventional NST. The sensitivity and specificity of Doppler as compared to NST is $82.6 \%$ and $63.0 \%$ respectively with a diagnostic accuracy of $72 \%$. In this study, Doppler has negative predictive value of $80.95 \%$ and positive predictive value of $65.5 \%$. Color Doppler has diagnostic accuracy of $72 \%$. The likelihood ratio of 2.23 is significant. The combination of umbilical and foetal cerebral Doppler indices may increase the utility of Doppler ultrasound in preeclamptic subjects.

Seyam et al conducted a study where in the diagnosis-todelivery interval was significantly shorter, and the average birth weight and gestational age at delivery were significantly lower, for foetuses with abnormal Doppler 
velocimetry (showing diminished or severely reduced/absent end-diastolic velocity) than for those in the normal Doppler group. ${ }^{9}$ Foetuses with abnormal Doppler velocimetry also had a significantly higher incidence of oligohydramnios, low-birth weight $\left(<10^{\text {th }}\right.$ percentile), and admission to the Neonatal Intensive Care Unit. Similar results were found in this study and were more evident in Group D, where both NST and the Doppler were abnormal, we had more number of NICU admissions, perinatal morbidity and mortality, prematurity and low birth weight.

A study conducted by Nomurarmy, et al in pregnancies with zero or reverse diastole in umbilical artery: analysis of perinatal outcomes, it was seen that reversal of flow carries higher incidences of perinatal and overall mortality and severe intrauterine growth retardation compared to the absent end diastolic flow group. ${ }^{10}$ Similarly, in this current study the mortality rate in reversal of diastolic flow was $77.77 \%$ and in absent UA flow was $16.66 \%$. Also, the incidence of having both FGR+PE were more $(88.88 \%)$ in the group where Color Doppler showed reversal of flow.

Doppler can detect foetal adaptations like Brain Sparing Effect (BSE) occurring early in the decompensation cascade. A low PI in MCA and/or cerebroplacental ratio $<1.08$ reflects it. In the study of 13 foetuses by Weiner et al six foetuses showed loss of BSE followed by development of abnormal foetal rate pattern. ${ }^{11}$ They compared foetal Doppler with computerized foetal heart rate monitoring. They opined that a loss of autonomic reactivity occurs first in the brain followed by similar response in the heart manifested by abnormalities in foetal heart patterns. Although only UA SD ratio was compared in the current study to predict the outcome, other Doppler parameters can also be taken into consideration to more accurately predict the outcome and timing the delivery.

Ott studied the single Doppler parameter MCA/UA S/D ratio in comparison with NST to predict the neonatal compromise, concluded that combination of NST and MCA/UA PI ratio was excellent predictor of perinatal outcome. ${ }^{12}$ In this current study, the number in Group $\mathrm{C}$ was too small $(n=4)$ to show the significance of abnormal NST with normal Doppler. Nevertheless, NST is useful to detect acute foetal distress due to abruption, cord compression, and foeto maternal haemorrhage, which are not rare in these high risk cases.

Tannirandorn $\mathrm{Y}$ et al did a study with a purpose to assess perinatal outcome in patients showing absent enddiastolic velocity (AEDV) and reversed end-diastolic velocity (REDV) in umbilical artery flow velocity waveforms over nineteen months. ${ }^{13}$ Fifteen patients, all in high risk pregnancies, were identified during this period; 9 with AEDV and 6 with REDV. Twelve babies died (3 foetal deaths, 4 stillbirths and 5 neonatal deaths), giving the perinatal mortality is this group as 80 per cent. The interval between the abnormal waveform recording and foetal death or delivery was between 2 hours and 4 weeks. In three foetuses with abnormal diastolic flow, analysis of umbilical vein blood gases revealed severe acidosis and hypoxia. In this current study 6/50 (12\%) foetuses were found to have AEDV in UA and among that $66.66 \%$ had both FGR+ PE as maternal complication. In this group there was $83.33 \%$ rate of LSCS, $16.66 \%$ neonatal mortality rate, $83.33 \%$ NICU stay rate and $66.66 \%$ complication rate in neonates. Whereas 9/50 (18\%) had REDV and among that $88.88 \%$ had both FGR+PE as maternal complication, a similar rate of LSCS, $77.77 \%$ rate of neonatal mortality, $100 \%$ NICU stay and $66.66 \%$ complication rate in the neonates. These findings suggest that once the diastolic component of umbilical artery flow velocity waveforms become absent or reversed, the foetuses is in a state of hypoxia and acidosis and perinatal outcome is catastrophic.

Foetal Doppler has the power to discriminate between sick and healthy foetuses and with serial measurements it is possible to monitor any deterioration in the foetus. In chronic hypoxia Doppler changes occur first while abnormal foetal heart tracings represent late signs of foetal deterioration. Disadvantages of Doppler technique are the requirement of sophisticated equipment and a degree of operator skill and expertise. They may not be available in all centres. Advantages of NST include ease of use and interpretation, low cost, and minimal time required. Therefore, it may remain the workhorse in detection of a compromised foetuses in many hospitals.

\section{CONCLUSION}

Doppler is useful in recognizing foetal compromise earlier than non-stress test giving a lead time which is important in the management of preterm high risk pregnancies. An abnormal NST following an abnormal Doppler is associated with the worst perinatal outcome. In cases with abnormal Doppler if the prospects for neonatal survival are good, it is better to deliver the foetuses before NST becomes abnormal. It was observed that in cases with normal Doppler, sudden abnormal NST indicates acute hypoxia. NST still holds its importance in foetal monitoring because of its ease of performance and cost effectiveness. But both the tests are complimentary to one another in foetal surveillance of high risk pregnancy. The clinical scenario however dictates the choice of the appropriate test. Other Doppler parameters like UA pulsatility index (PI), the Middle Cerebral Artery (MCA) PI, the ratio of MCA PI to UA PI and Ductus Venosus flow studies can also be incorporated along with NST for better prediction of foetal compromise in -utero and for timing the delivery. Combined foetal testing modalities such as Doppler, NST and biophysical profile provide a wealth of information regarding foetal health. Integrated foetal testing would be ideal for individualized care of the preterm compromised foetus for timed intervention. 
Funding: No funding sources

Conflict of interest: None declared

Ethical approval: The study was approved by the Institutional Ethics Committee

\section{REFERENCES}

1. Denis KL, Dudley. Assessment of foetuses in utero, Oxorn-Foote Human Labour and birth, $5^{\text {th }}$ ed. Tata Mc Graw Hill; 2010:597.

2. Pillai M, James D. The development of foetal heart rate patterns During normal pregnancy. Obstet Gynecol. 1990;76:812-6.

3. Westgate JA, Wibbens B, Bennett L, Wassink G, Parer JT, Gunn AJ. The intrapartum deceleration in center stage: a physiologic approach to the interpretation of foetal heart rate changes in labor. Am J Obstet Gynecol. 2007;197(3):236.e1-11.

4. Ertan AK, He JP, Tanriverdi HA, Hendrik J, Limbach HG, Schmidt W. Comparison of perinatal outcome in fetuses with reverse or absent enddiastolic flow in the umbilical artery and/or fetal descending aorta. J Perinat Med. 2003;31(4):307-12.

5. Nomura RMY, Francisco RPV, Miyadahira SM. Mathematical model for prediction of metabolic acidosis at birth in pregnancies with diastolic zero or reverse. Rev Bras Gynecol Obstet. 2002;24(4):261-9.

6. The GRIT study group. A randomized trial of timed delivery for the compromised preterm foetuses; short-term outcomes and Baysian interpretation. BJOG. 2003;110:27-32.

7. Arduini D, Rizzo G, Romanini C. The development of abnormal heart rate patterns after absent end diastolic velocity in umbilical artery: Analysis of risk factors. Am J Obstet Gynecol. 1993;168:43-50.
8. Ozeren M, Dinç H, Ekmen U, Senekayli C, Aydemir V. Umbilical and middle cerebral artery Doppler indices in patients with preeclampsia. Eur J Obstet Gynecol Reprod Biol. 1999;82(1):11-6.

9. Seyam YS, Al-Mahmeid MS, Al-Tamimi HK. Umbilical artery Doppler flow velocimetry in intrauterine growth restriction and its relation to perinatal outcome. Int $\mathbf{J}$ Gynaecol Obstet. 2002;77(2):131-7.

10. Nomura RMY, Francisco RPV, Miyadahira SM. Cardiotocography in pregnancies with zero or reverse diastole in umbilical artery: analysis of perinatal outcomes. Rev Assoc Med Bras. 2003;49(1):79-85.

11. Weiner Z, Farmakides G, Schulman H, Penny B. Central and peripheral hemodynamic changes in foetuses with absent end-diastolic velocity in umbilical artery: correlation with computerized foetal heart rate pattern. Am J Obstet Gynecol. 1994;170:509-15.

12. Ott WJ. Comparison of the non-stress test with the evaluation of centralization of blood flow for the prediction of neonatal compromise. Ultrasound Obstet Gynecol. 1999;14:38-41.

13. Phaosavasdi S, Taneepanichsakul S, Witoonpanich P, Tannirandorn Y, Pruksananonda K, Uerpairojkit B et al. Assessment of medical ethics of fourth-year medical students. J Med Assoc Thai. 1994;77(2):816.

Cite this article as: Raj A, Bhat RK, Prajwal S, Rao PS. Foetal umbilical artery doppler versus NST as predictors of adverse perinatal outcome in severe preeclampsia and foetal growth restriction. Int J Reprod Contracept Obstet Gynecol 2017;6:2060-6. 